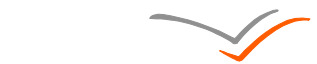

VERSITA
GEOCHRONOMETRIA 41(3) 2014: 256-264

DOI 10.2478/s13386-013-0157-y

Available online at

www.springerlink.com

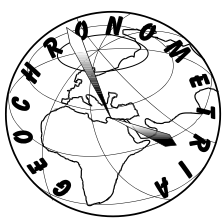

\title{
DIFFERENT APPROACHES TO DATE BRICKS FROM HISTORICAL BUILDINGS
}

\author{
GIUSEPPE STELLA ${ }^{1}$, DOROTEA FONTANA ${ }^{1,2}$, \\ ANNA MARIA GUELI ${ }^{1}$ and SEBASTIANO OLINDO TROJA ${ }^{\mathbf{1}}$

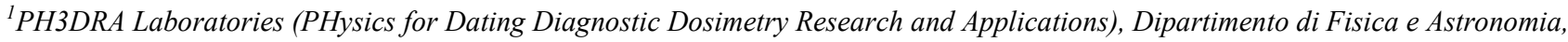 \\ Università di Catania \& INFN Sezione di Catania, via Santa Sofia 64, 95123 Catania, Italy \\ ${ }^{2}$ Laboratorio di Fisica e Tecnologie relative - UniNetLab, Dipartimento di Fisica e Chimica, Università degli Studi di Palermo, \\ Viale delle Scienze, Edificio 18, 90128 Palermo, Italy
}

Received 2 August 2013

Accepted 6 February 2014

\begin{abstract}
The application of Thermally (TL) and Optically (OSL) Stimulated Luminescence on bricks used as building material has allowed solving an chronological issue in the field of historical building dating.

The possibility to use one or more methodologies of dating is closely related to the luminescent and granulometric characteristics of the sample. Using some brick samples collected in the church of Sain Seurin in Bordeaux (France), this paper discusses the implications and the possibility to use different approaches and techniques for dating. With this aim luminescence measurements were performed on both polymineral fine grain and quartz inclusion phases extracted from each brick. For Equivalent Dose (ED) and consequently age determination, TL on mixed fine grain fraction (FG), OSL on quartz inclusions $(\mathrm{QI})$ and on mixed fine grain $\left(\mathrm{FG}^{*}\right)$ fraction, were used. The results obtained suggest the advantage of using OSL technique on fine grain fraction cleaned up by IR stimulation (FG*), but the use of quartz inclusion represents indeed a good alternative.
\end{abstract}

Keywords: luminescence dating, polymineral fine grain technique, IR stimulation time, [Post-IR] OSL, quartz inclusion technique, preheat plateau.

\section{INTRODUCTION}

The historical building dating is usually indirectly made by thermally stimulated luminescence techniques (TL) on polymineral fine grained phases extracted from bricks. The first step of the application of this technique was made by Goedicke et al. (1981) on Venetian villas (north Italy) dated from the $15^{\text {th }}$ to the $17^{\text {th }}$ centuries. The results appear both precise and accurate using the polymineral fine-grain technique. This was confirmed by other

Corresponding author: G. Stella

e-mail: giuseppe.stella@ct.infn.it dating works on European historical buildings located in Denmark (Abrahamsen et al., 1998), Czech Republic (Cechák et al., 2000), Finland (Hutt et al., 2001), Germany (Göksu and Schwenk, 2001) and Italy (Martini and Sibilia, 2001).

Some authors (Bailiff and Holland, 2000; Bailiff, 2007) found the reliability of this technique when applied to English ceramic materials to be inconsistent. They, alternatively, used optically stimulated luminescence techniques (OSL) coupled with Single Aliquot Regeneration (SAR) protocol (Murray and Wintle, 2000, 2003) on quartz inclusions extracted from brick, obtaining advantages in terms of signal sensitivity compared with thermoluminescence (TL) ones. 
Starting from a polymineral fine grained phase, etching procedures were used to remove the feldspar component with good results (Prasad, 2000; Mauz and Lang, 2004) and then was possible to apply OSL measurements and SAR protocol for the determination of the equivalent dose. However the attempts to remove feldspars using various chemical etching procedures have generally not yielded satisfactory samples. Prasad (2000) describes an HF treatment procedure for dissolution of fine grained feldspars from polymineral samples with mixtures of quartz and different percentages of feldspars. The results obtained suggest that only samples with up to $40 \%$ of feldspars have a high chance of success using etching procedures. In the case of high feldspars contamination is useful to use, for the equivalent dose determination, postIRSL measurement techniques applied to not etched polymineral fine grain fractions, reported in the literature as double SAR measurement protocol (dSAR) (Zhang et al., 2007; Zhang and Zhou, 2007).

In recent years, the development of multiple independent measurement techniques used on the same sample has led to process of intercomparison between different research groups (Guibert et al., 2009).

The aim of this study was to apply different independent methodologies on each sample in order to reach greater reliability of the final dating results through a comparison between standard thermoluminescence (TL) and optical stimulated (OSL) measurements on different granulometric fractions (polymineral fine grained and quartz inclusions). This approach assumes an even more important role if only a small number of samples can be collected.

\section{EQUATION AGE}

The use of different granulometric phases, regardless of the methods used (TL or OSL), involves different age equations.

In the case of fine grain polymineral fraction we have:

$$
\text { Age }=E D /\left(k \cdot D_{\alpha}+D_{\beta}+D_{\gamma+\operatorname{cosm}}\right)
$$

where $E D$ is the equivalent dose and $k$ is the alpha efficiency, different for TL and OSL measurements. $D_{\alpha}$ and $D_{\beta}$ are respectively, the annual dose contributions derived from alpha and beta decay of the radioactive contents present in the sample and that together give the annual dose from the sample itself. $D_{\gamma}$ is the contribution to the annual dose resulting from gamma emissions of the radioactive material present in the environment. The cosmic dose value is mainly due to the latitude and the depth from the Earth's surface (Prescott and Hutton, 1988).

In the case of quartz inclusion, or more generally of coarse grain, we have:

Age $=E D /\left(f \cdot D_{\beta}+D_{\gamma+\operatorname{cosm}}\right)$

where $f$ is the attenuation factor depending on grain size (Mejdahl, 1979). All dose contributions to the annual dose must be corrected by factors that take into account the porosity of the sample and the average moisture level of the sample during its life.

\section{MATERIALS AND METHODS}

The samples analysed, identified as STS\#TL4, STS\#TL5 and STS\#TL6, are part of a more comprehensive research program within the European research network (GdRE) "Architectural ceramics and dating methods" which involves many European groups working in the field of historical building's dating (Guibert et al., 2009). They come from the church of Saint Seurin (Bordeaux, France), dated by historians around the sixth century. It is one of the oldest religious buildings of Bordeaux which has been renovated and rebuilt between the twelfth and fourteenth centuries. The site is today used as an underground museum of Christian origins of Bordeaux.

Sampling was done in the area under the crypt of the church, where, during an excavation, a Christian burial ground of about $400 \mathrm{~m}^{2}$ was found.

Table 1 shows the details for the samples studied with ID number, sampling area and photo of the sampling points.

\section{Sample preparation}

After removal external $2 \mathrm{~mm}$ the samples were mechanically crushed using an agate mortar. The crushed material was sieved in order to obtain $\varnothing<40 \mu \mathrm{m}$ and $90<\varnothing<150 \mu \mathrm{m}$ granulometric fractions. The $\varnothing<40 \mu \mathrm{m}$ fraction was used to obtain the polymineral fine grained phase and the $90<\varnothing<150 \mu \mathrm{m}$ fraction was used for the extraction of quartz inclusions. Both the fractions were etched in $10 \% \mathrm{HCl}$ for 100 minutes, then in $10 \% \mathrm{H}_{2} \mathrm{O}_{2}$ for 48 hours in order to eliminate, respectively, carbonate phase and organic part.

The $\varnothing<40 \mu \mathrm{m}$ fraction was further separated into two parts. According with standard procedures the first part (used for TL measurements) was etched in $1 \% \mathrm{HF}$

Table 1. ID sample number, sampling area and photo of the sampling points in Saint Seurin Church (Bordeaux, France).

\begin{tabular}{|c|c|c|c|c|}
\hline Site & \begin{tabular}{|c|} 
ID \\
Sample \\
\end{tabular} & Sample & \begin{tabular}{|c|}
$\begin{array}{c}\text { Sampling } \\
\text { point }\end{array}$ \\
\end{tabular} & Photo \\
\hline \multirow{3}{*}{$\begin{array}{c}\text { Saint Seurin } \\
\text { (Bordeaux, } \\
\text { France) }\end{array}$} & STS\#TL4 & Brick & \multirow{3}{*}{$\begin{array}{l}\text { Saint Fort } \\
\text { Cenotaph } \\
\text { (Floor- } \\
\text { East side) }\end{array}$} & \\
\hline & STS\#TL5 & Brick & & \\
\hline & STS\#TL6 & Brick & & \\
\hline
\end{tabular}


for one hour and then in $10 \% \mathrm{HCl}$ for 25 minutes to remove eventual fluorosilicates. So with a process of sedimentation in acetone, according to Stokes' law, polymineral fine grained $4<\varnothing<11 \mu \mathrm{m}$ fraction (FG) was obtained (Aitken, 1985; Guibert et al., 2009; Gueli et al., 2009; 2010).

The second $\varnothing<40 \mu \mathrm{m}$ part was not etched in HF and the $4<\varnothing<11 \mu \mathrm{m}$ sedimented fraction (FG*) was used for OSL measurements (Aitken, 1998).

Starting from the $90<\varnothing<150 \mu \mathrm{m}$ range mineralogically undifferentiated phase, the quartz inclusion fraction (QI) was obtained after different steps. Using different densities of sodium polytungstate solution, quartz was separated from feldspars and other silicate minerals; afterwards it was etched in $\mathrm{HF}(40 \%, 45 \mathrm{~min})$, to remove the external layers and the consequent alpha dose contribution, and then washed in $\mathrm{HCl}(10 \%, 25 \mathrm{~min})$ to eliminate any fluorides produced (Bailiff and Holland, 2000; Bailiff, 2007).

\section{Application of TL dating technique to polymineral fine grain}

FG was used for TL dating applying the added dose technique for ED determination (FG-TL-AD) (Aitken, 1985; Guibert et al., 2009). For each sample, aliquots were prepared; the first 6 were subjected to the natural thermoluminescence reading and the others, divided in groups of 6 , were irradiated with increasing $\beta$ doses, and then their thermoluminescent signals were read. TL glow curves were recorded by heating the aliquots up to $500{ }^{\circ} \mathrm{C}$ with a $5^{\circ} \mathrm{C} / \mathrm{s}$ heating rate in a nitrogen environment. In order to eliminate the variation of luminescence intensity, due to the small different mass of grains deposed on the aliquots, normalization sequence was made giving the same dose to all the aliquots (Atken, 1985). Temperature region from $300-350^{\circ} \mathrm{C}$ (with $280-370^{\circ} \mathrm{C}$ plateau region) was used for the construction of the growth line TL intensity $v s$ dose and the subsequent extrapolation of the $Q_{\beta}$ value (Fig. 1). This last value represents the artificial beta dose needed to obtain a TL signal equivalent to the natural luminescence emission due total absorbed dose. In order to evaluate the possible non-linearity behaviour of the sample at low artificial beta doses, $q_{\beta}$ correction was determined from the intercept of the "second" growth curve behaviour (Fig. 1) (Aitken, 1985; Guibert et al., 1996). $E D$ of (1) was calculated adding $Q_{\beta}$ and $q_{\beta}$ values. For each sample a study of fading was carried out by comparing the TL signals of irradiated aliquots and those analyzed with a delay of $15,30,40$ and 45 days between the end of irradiation and the TL measurements (Aitken, 1985). From artificial luminescence signals induced by calibrated beta and alpha doses the luminescence efficiency coefficient $k$, necessary to correct the alpha dose contribution to the annual dose, was determined (Guibert et al., 2009).

\section{Application of the OSL dating technique to poly- mineral fine grain}

Due to the different luminescent optical characteristics of quartz and feldspars is necessary to separate their OSL signals to obtain useful quartz dose estimates. FG* was used for OSL dating applying double SAR protocol (FG*-OSL-dSAR) (Roberts and Wintle, 2001; Zhang and Zhou, 2007; Kim et al., 2009).

To check the degree of feldspars contamination in $\mathrm{FG}^{*}$ fraction, the coefficient $\mathrm{R}$ was calculated on a group of three aliquots for each sample. It is determined by the ratio between the normalized OSL intensity after IR stimulation (post-IR OSL/ $\mathrm{T}_{2}$ ) and the normalized OSL emission (OSL/ $\mathrm{T}_{1}$ ) (Mauz and Lang, 2004). OSL/ $\mathrm{T}_{1}$ represents the OSL signal normalized by $\mathrm{T}_{1}$ test dose and post-IR OSL/ $\mathrm{T}_{2}$ the OSL emission obtained after IR stimulation normalized by $\mathrm{T}_{2}$ test dose.

So, in order to eliminate feldspars luminescent contribution, for $E D$ determination, before each blue-light OSL stimulation (BOSL) measurement, IR stimulation was applied (dSAR procedure) (Roberts and Wintle, 2001; Zhang et al., 2007). Before dSAR procedure, a test to identify the optimal IR stimulation time was undertaken (Wang et al., 2006). The optimal duration of IR exposure for each sample was chosen considering the results obtained using different times in the range $100-500 \mathrm{~s}$ at a temperature of $50^{\circ} \mathrm{C}$ (Roberts, 2007; Kim et al., 2009).

Because thermal treatment prior to measurements may transfer charge from light-insensitive traps to lightsensitive ones, it is important to investigate the influence of preheating required by $E D$ determination procedures (Murray and Wintle, 2000). Preheat plateau tests were conducted for both samples in this study using the dSAR measurement protocol (Table 2) (Zhang and Zhou, 2007)

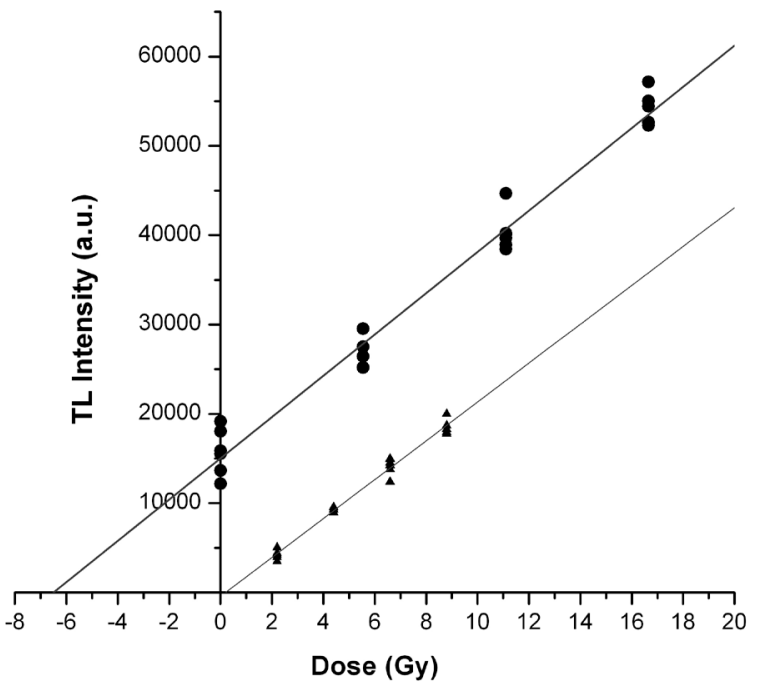

Fig. 1. Equivalent beta dose determination by added dose technique of the STS_TL\#4 sample: $Q_{\beta}$ (circles) and $q_{\beta}$ (triangles) evaluation from growth curves. 
across a range of temperatures from $140^{\circ} \mathrm{C}$ to $260^{\circ} \mathrm{C}$ for $10 \mathrm{~s}$. A cut heat of $160^{\circ} \mathrm{C}$ was used after the test dose. An IR stimulation duration of $250 \mathrm{~s}$ at $50^{\circ} \mathrm{C}$ was employed as discussed above.

\section{Application of the OSL dating technique to quartz inclusions}

The purity of QI fraction was verified by infrared stimulation on some aliquots of each sample (Aitken, 1998). Following the SAR procedure, the $E D$ values were then obtained by OSL technique (QI-OSL-SAR) (Murray and Wintle, 2000, 2003). The OSL signal of QI is normally measured following a relatively low preheating treatment, typically from 200 to $220^{\circ} \mathrm{C}$ for $10 \mathrm{~s}$ (Bailiff and Holland, 2000; Murray and Clemmensen, 2001; Ramzaev et al., 2008; Wallinga et al., 2001). These low temperatures are justified in order to limit the heating transfer of charge from deep traps to the OSL traps which influences significantly the dating of this kind of samples (Rhodes, 2000; Murray and Clemmensen, 2001; Wallinga et al., 2001).

For all the samples, the ED variation vs. preheating temperature were evaluated. The aliquots of each sample were grouped in four and each group was subjected to the SAR protocol measurements using different preheating temperatures from 140 to $260^{\circ} \mathrm{C}$ for $10 \mathrm{~s}$ (Kiyak and Canel, 2006). The cycle of SAR protocol was repeated 5 times using increasing regeneration doses $D_{\mathrm{i}}$ from 2 to $10 \mathrm{~Gy}$ with a test dose of $1 \mathrm{~Gy}$. A cut heat of $160^{\circ} \mathrm{C}$ was applied after the test dose.

QI-OSL-SAR subsamples were measured using a SAR procedure as outlined in Table 2, but omitting steps 3 and 7, and using a preheat of $180^{\circ} \mathrm{C}$ in step 2. Each $E D$ value is the weighted average of 16 aliquots.

\section{Recovery test}

An experimental procedure to detect possible atypical response of each sample at dose values is necessary. This

Table 2. Sequence used to measure the $L_{i} T_{i}$ signals necessary to obtain ED from FG*-OSL-dSAR subsamples.

\begin{tabular}{lll}
\hline Step & Treatment & Observed \\
\hline 1 & Give dose $\left(0 \mathrm{~Gy}\right.$ for natural signals), $D_{\mathrm{i}}$ & - \\
\hline 2 & Preheat $\left(140-260^{\circ} \mathrm{C}\right.$ for $\left.10 \mathrm{~s}\right)$ & - \\
\hline 3 & Stimulate with IR light for $250 \mathrm{~s}$ at $50^{\circ} \mathrm{C}$ & - \\
\hline 4 & Stimulate with blue light for $40 \mathrm{~s}$ at $125^{\circ} \mathrm{C}$ & $\begin{array}{l}\mathrm{L}_{\mathrm{i}} \\
\text { [post-IR] OSL }\end{array}$ \\
\hline 5 & Give test dose, $1 \mathrm{~Gy}$ & - \\
\hline 6 & Cut heat to $160^{\circ} \mathrm{C}$ & - \\
\hline 7 & Stimulate with IR for $250 \mathrm{~s}$ at $50^{\circ} \mathrm{C}$ & - \\
\hline 8 & Stimulate with blue light for $40 \mathrm{~s}$ at $125^{\circ} \mathrm{C}$ & - \\
\hline 9 & $\begin{array}{l}\text { Repeat steps } 1-8 \text { for } 5 \text { times for regeneration } \\
\text { doses in the range } 0-10 \text { Gy. }\end{array}$ & $\mathrm{T}_{\mathrm{i}}$ \\
\hline $\mathrm{L}_{\mathrm{i}}$ and $\mathrm{T}_{\mathrm{i}}$ were derived from the decay curves, taking the first $0.8 \mathrm{~s} \mathrm{minus} \mathrm{a}$ \\
background estimated from the last 3.5 s integral of the OSL signal. $\mathrm{L}_{i} / \mathrm{T}_{i}$ is the \\
sensitivity-corrected [post-IR] OSL intensity.
\end{tabular}

could in fact influence the Single Aliquot Regeneration procedure results. In this work the Recovery test was used.

The dose recovery test consists on the application of SAR on QI grains and dSAR on FG* fractions on aliquots to which a laboratory dose has been given followed by optical bleaching (Murray and Wintle, 2003). In such a test, the ratio of the measured to given dose should be closer to unity.

Three aliquots of each sample were bleached by LED blue light stimulation at room temperature for $10000 \mathrm{~s}$. Later, to the same aliquots, a known dose was administered and then, using the same experimental conditions discussed in the previous sections for both quartz and polymineral fine grain fraction, $E D$ values were measured.

Table 3 summarizes the range-size, the etching procedure and the type of analyses performed on each sample.

\section{Annual dose components}

The alpha contribution to the annual dose was calculated from the natural $\mathrm{U}$ and $\mathrm{Th}$ contents measured by ICP-MS using the conversion factors of Guérin et al. (2011). This value was compared with the data obtained on thick sample layer using $\mathrm{ZnS}$ scintillating discs by an integral alpha counter system (Alpha Counter Unit AL03 model, AEDI, Milano, Italy). This reader allows also coincidence measurements useful to discriminate the alpha contributions coming from both $\mathrm{U}$ and Th chains. Indications about possible disequilibrium of $U$ chain were obtained from the comparison between the two evaluated $\mathrm{U}$ alpha contributions (Aitken, 1985; Feathers et al., 2008; Stella et al., 2013). K contribution to the beta annual dose was calculated from the content assessed by FUS-ICP (Fusion with lithium borate for ICP) using the conversion factors cited above.

All the dose contributions were corrected on the basis of the porosity factor $(W)$ measured experimentally (Aitken, 1985) and water saturation factor $(F)$ chosen on the basis of sampling point (height, inside and outside, etc.) and water content evaluation of each sample at the excavation. In this particular case an $F$ value of $0.5 \pm 0.2$ was chosen. W was calculated measuring the weight of a fragment under different conditions of damp: totally dry (after having it kept in oven to $40^{\circ} \mathrm{C}$ for 48 hours) and in saturation (after having left it in water until weight changes of the sample were not found).

The annual environmental dose rate was measured using very sensitive TL dosimeters $\left(\mathrm{CaSO}_{4}\right)$ enclosed in capsules placed in situ at the sampling points (Guibert et al., 2009; Gueli et al., 2009; 2010). Cosmic radiation was calculated according with Prescott and Hutton (1988). The building is located at $44^{\circ} 50^{\prime} 36^{\prime \prime} \mathrm{N}$ latitude and the cover thickness over the sampling area is represented only by the fabric roof. No depth correction was then considered. 
Table 3. Procedures code, range size, etching procedure and analyses performed on each sample.

\begin{tabular}{|c|c|c|c|c|}
\hline Sample & Procedures & Range size & Etching procedure & Analyses performed \\
\hline \multirow{3}{*}{ STS\#TL4 } & FG-TL-AD & $4<\varnothing<11 \mu \mathrm{m}$ & $\begin{array}{l}\text { - } 10 \% \mathrm{HCl} \text { for } 100 \mathrm{~min} \\
\text { - } 1 \% \mathrm{HF} \text { for } 1 \text { hour } \\
\text { - } 10 \% \mathrm{HCl} \text { for } 25 \mathrm{~min}\end{array}$ & $\begin{array}{l}\text { - TL with Added Dose technique for ED measure- } \\
\text { ments } \\
\text { - Non linearity correction } \\
\text { - Fading study }\end{array}$ \\
\hline & $F^{*}-O S L-d S A R$ & $4<\varnothing<11 \mu \mathrm{m}$ & - $10 \% \mathrm{HCl}$ for $100 \mathrm{~min}$ & $\begin{array}{l}\text { - Feldspar contamination test } \\
\text { - Preheat plateau test } \\
\text { - [post-IR] OSL ED as a function of IR stimulation } \\
\text { time } \\
\text { - dSAR method for ED determination } \\
\text { - Recovery test }\end{array}$ \\
\hline & QI-OSL-SAR & $90<\varnothing<150 \mu \mathrm{m}$ & $\begin{array}{l}\text { - } 10 \% \mathrm{HCl} \text { for } 100 \mathrm{~min} \\
\text { - } 40 \% \mathrm{HF} \text { for } 45 \mathrm{~min} \\
\text { - } 10 \% \mathrm{HCl} \text { for } 25 \mathrm{~min}\end{array}$ & $\begin{array}{l}\text { - Feldspar contamination test } \\
\text { - Preheat plateau test } \\
\text { - SAR method for ED determination } \\
\text { - Recovery test } \\
\end{array}$ \\
\hline \multirow{3}{*}{ STS\#TL5 } & FG-TL-AD & $4<\varnothing<11 \mu \mathrm{m}$ & $\begin{array}{l}\text { - } 10 \% \mathrm{HCl} \text { for } 100 \mathrm{~min} \\
\text { - } 1 \% \mathrm{HF} \text { for } 1 \text { hour } \\
\text { - } 10 \% \mathrm{HCl} \text { for } 25 \mathrm{~min}\end{array}$ & $\begin{array}{l}\text { - TL with Added Dose technique for ED measure- } \\
\text { ments } \\
\text { - Non linearity correction } \\
\text { - Fading study }\end{array}$ \\
\hline & FG*-OSL-dSAR & $4<\varnothing<11 \mu \mathrm{m}$ & - $10 \% \mathrm{HCl}$ for $100 \mathrm{~min}$ & $\begin{array}{l}\text { - Feldspar contamination test } \\
\text { - Preheat plateau test } \\
\text { - [post-IR] OSL ED as a function of IR stimulation } \\
\text { - } \text { dime } \\
\text { - RSAR method for ED determination } \\
\text { Recovery test }\end{array}$ \\
\hline & QI-OSL-SAR & $90<\varnothing<150 \mu \mathrm{m}$ & $\begin{array}{l}\text { - } 10 \% \mathrm{HCl} \text { for } 100 \mathrm{~min} \\
\text { - } 40 \% \mathrm{HF} \text { for } 45 \mathrm{~min} \\
\text { - } 10 \% \mathrm{HCl} \text { for } 25 \mathrm{~min}\end{array}$ & $\begin{array}{l}\text { - Feldspar contamination test } \\
\text { - Preheat plateau test } \\
\text { - SAR method for ED determination } \\
\text { - Recovery test } \\
\end{array}$ \\
\hline \multirow{3}{*}{ STS\#TL6 } & FG-TL-AD & $4<\varnothing<11 \mu \mathrm{m}$ & $\begin{array}{l}\text { - } 10 \% \mathrm{HCl} \text { for } 100 \mathrm{~min} \\
\text { - } 1 \% \mathrm{HF} \text { for } 1 \text { hour } \\
\text { - } 10 \% \mathrm{HCl} \text { for } 25 \mathrm{~min}\end{array}$ & $\begin{array}{l}\text { - TL with Added Dose technique for ED measure- } \\
\text { ments } \\
\text { - Non linearity correction } \\
\text { - Fading study }\end{array}$ \\
\hline & $F^{*}-O S L-d S A R$ & $4<\varnothing<11 \mu \mathrm{m}$ & - $10 \% \mathrm{HCl}$ for $100 \mathrm{~min}$ & $\begin{array}{l}\text { - Feldspar contamination test } \\
\text { - Preheat plateau test } \\
\text { - [post-IR] OSL ED as a function of IR stimulation } \\
\text { time } \\
\text { - dSAR method for ED determination } \\
\text { - Recovery test }\end{array}$ \\
\hline & QI-OSL-SAR & $90<\varnothing<150 \mu \mathrm{m}$ & $\begin{array}{l}\text { - } 10 \% \mathrm{HCl} \text { for } 100 \mathrm{~min} \\
\text { - } 40 \% \mathrm{HF} \text { for } 45 \mathrm{~min} \\
\text { - } 10 \% \mathrm{HCl} \text { for } 25 \mathrm{~min}\end{array}$ & $\begin{array}{l}\text { - Feldspar contamination test } \\
\text { - Preheat plateau test } \\
\text { - SAR method for ED determination } \\
\text { - Recovery test }\end{array}$ \\
\hline
\end{tabular}

\section{Instruments}

All measurements were performed using TL-DA-10 and TL-DA-15 automated Risø readers equipped with EMI 9235QA photomultipliers (Bøtter-Jensen, 1997; Bøtter-Jensen et al., 2000). TL glow curves were recorded in the TL-DA-10 detection system using Corning 7-59 and Schott BG-12 optical filters. OSL and IRSL signals were obtained using TL-DA-15 detection system using, respectively, 41 blue LEDs $(470 \pm 30 \mathrm{~nm})$ and a laser diode $(830 \pm 10 \mathrm{~nm})$. The stimulation units delivered $\sim 30 \mathrm{mWcm}^{-2}$ for OSL and $\sim 240 \mathrm{mWcm}^{-2}$ for IRSL at $90 \%$ power. Both OSL and IRSL emissions were detected in the $260-390 \mathrm{~nm}$ region using an Hoya U340 optical filter. Artificial irradiation was performed with an external ${ }^{241} \mathrm{Am}$ calibrated alpha source delivering $2.7 \mathrm{~Gy} / \mathrm{min}$ and two ${ }^{90} \mathrm{Sr}-{ }^{90} \mathrm{Y}$ calibrated beta sources integrated in the TL-DA-10/15 systems delivering, respectively, $1.2 \mathrm{~Gy} / \mathrm{min}$ and $6 \mathrm{~Gy} / \mathrm{min}$. 


\section{RESULTS}

\section{TL measurements}

Fig. 1 shows, for sample STS TL\#4, the straight growth lines from which the beta equivalent dose $Q_{\beta}$ (a) and the correction $q_{\beta}$ (b) were obtained. The parallelism between the two straight growth lines, obtained for each sample, excludes sensitivity changes of the samples due to various heating cycles. No fading was observed within the limits of experimental errors for the bricks tested.

\section{OSL measurements}

\section{$F G^{*}-O S L-d S A R$}

The choice to remove the luminescent signal due to feldspars with IR stimulation rather than etching procedures during the sample preparation phase is due to the significant $R$ coefficient values obtained for the three samples: $0.38 \pm 0.02$ for STS_TL\#4, $0.39 \pm 0.02$ for STS TL\#5 and $0.42 \pm 0.03$ for STS TL\#6.

Fig. 2 shows the change in [post-IR] OSL ED as a function of IR stimulation time for the STS_TL\#4 sample. The $E D$ increases from a value of $\sim 3.5 \overline{\text { Gy }}$ when no IR stimulation is used and it reaches a value of $\sim 4.75 \mathrm{~Gy}$ after $250 \mathrm{~s}$ of IR stimulation. The ED plateau obtained at longer IR stimulation times (from $250 \mathrm{~s}$ to $500 \mathrm{~s}$ ) suggests the choice of the $250 \mathrm{~s}$ IR stimulation time in the dSAR protocol. This result was obtained for all three samples.

This is validated by the behaviour of [post-IR] OSL decay curves obtained for the same sample at different IR stimulation time compared to the quartz inclusion ones. In fact the initial OSL signal corresponding to IR stimula-

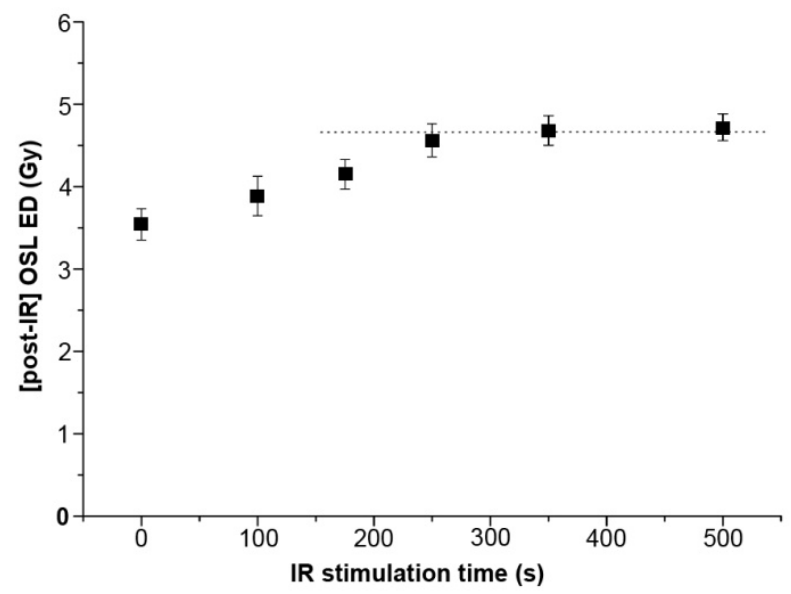

Fig. 2. Post-IR OSL ED values for FG fraction of STS_TL\#4 sample, determined for different IR stimulation times after a preheating of $200^{\circ} \mathrm{C}$ for $10 \mathrm{~s}$. Each point is the average result from three aliquots (1 $\sigma$ deviation), and the corresponding error is calculated using Analyst version 3.24 (Duller, 2007). The dotted line is the mean of the data points from $250 \mathrm{~s}$ to $500 \mathrm{~s}$. tion time $\leq 250$ s shows differences due to more rapid decay of the quartz respect to feldspars (Fig. 3) (Roberts, 2007; Kim et al., 2009).

Plateau tests carried out for the three samples (STS_TL\#4, STS_TL\#5 and STS_TL\#6) show that, considering the experimental errors, no significant changes in the average $E D$ value in the whole range of investigation (Fig. 4). A preheat temperature of $200^{\circ} \mathrm{C}$ for $10 \mathrm{~s}$ are used for $E D$ measurements.

So, the $E D$ values considered for dating obtained by dSAR method (range dose from 0 to $10 \mathrm{~Gy}$ ), based on the results of the tests made, were determined using preheating temperature at $200^{\circ} \mathrm{C}$ for $10 \mathrm{~s}$ and IR stimulation at

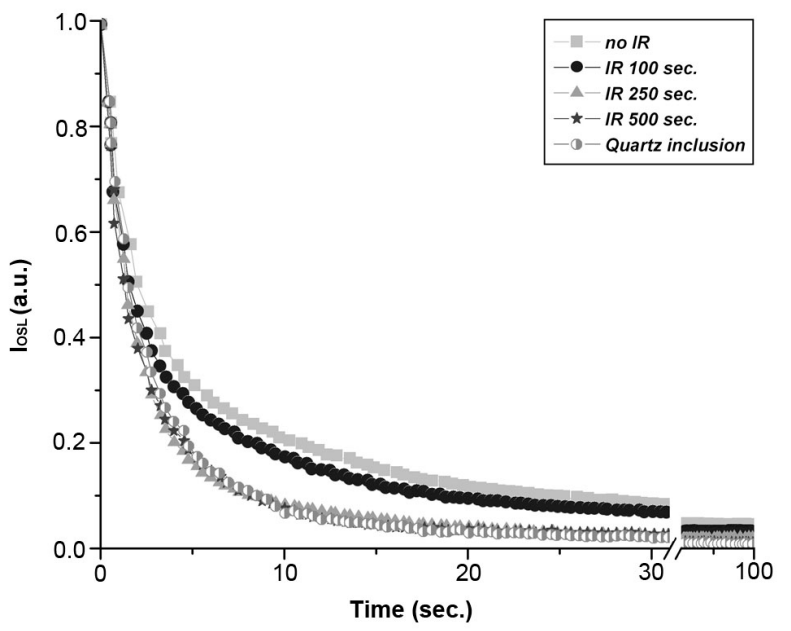

Fig. 3. The [post-IR] OSL decay curves for the data shown in Fig. 2 related to STS_TL\#4 sample. The OSL decay curves from FG* and from QI fraction are compared for IR stimulation times from 0 to $500 \mathrm{~s}$.

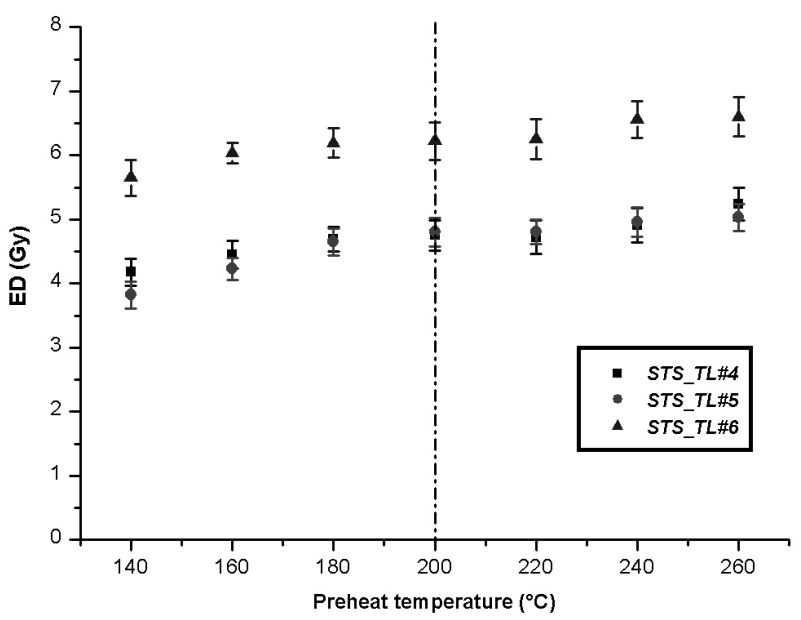

Fig. 4. ED values (1 $\sigma$ deviation) obtained on $F G^{*}$-OSL-dSAR subsample for STS_TL\#4, STS_TL\#5 and STS_TL\#6 samples as a function of preheating temperature. 
$50^{\circ} \mathrm{C}$ for $250 \mathrm{~s}$. Each $E D$ value is the weighted average of 24 aliquots.

\section{QI-OSL-SAR}

An example of plateau test, for the sample STS_TL\#4, is reported in Fig. 5. It not show significant variations of $\mathrm{ED}$ values within the experimental error in the range $160-200^{\circ} \mathrm{C}$, while at higher temperatures the $E D$ increases. Therefore a preheat of $180^{\circ} \mathrm{C}$ was adopted.

\section{Recovery test}

The dose recovery test confirms the reliability of the measuring parameters used for both SAR and dSAR procedures. For each sample, the value of ratio $R$ is closely to 1 (Fig. 6).

\section{Annual dose components}

The alpha doses obtained from ICPMass procedures are in good agreement with Alpha counting data within the experimental errors confirming the $U$ chain radioactive equilibrium (Table 4). So, the alpha dose rate obtained from $\mathrm{U}$ and Th contents (ICP-Mass) and the internal beta dose from $\mathrm{U}, \mathrm{Th}, \mathrm{K}$ and $\mathrm{Rb}$ were determined.

Table 5 shows the experimentally measured porosity factor $(W)$, the saturation factor $(F)$ chosen, the $\mathrm{k}$ value,

Table 4. Comparison between internal alpha dose rate values calculated by ICMass and measured by alpha counting system to obtain percentage difference $(\Delta \%)$.

\begin{tabular}{cccc}
\hline \multirow{2}{*}{ ID } & \multicolumn{3}{c}{ Alpha dose rate (mGy/a) } \\
\cline { 2 - 4 } & From ICPMass content & Alpha counting & $\Delta \%$ \\
\hline STS_TL\#4 & $20.96 \pm 0.83$ & $20.18 \pm 0.78$ & 3.70 \\
STS_TL\#5 & $21.73 \pm 0.86$ & $20.99 \pm 0.73$ & 3.36 \\
STS_TL\#6 & $15.58 \pm 0.60$ & $16.12 \pm 0.59$ & 3.49 \\
\hline
\end{tabular}

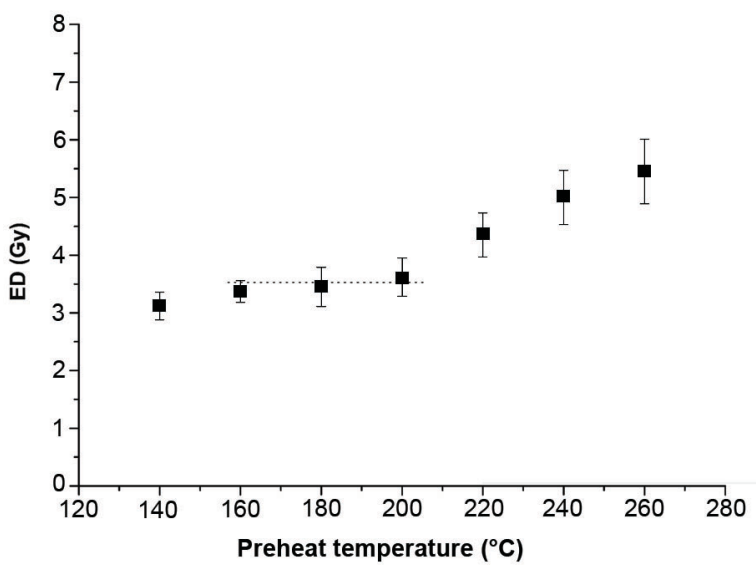

Fig. 5. ED values (10 deviation) obtained on QI-OSL-SAR subsample for STS_TL\#4 sample as a function of preheating temperature. The dotted line shows the ED plateau region. the internal dose contributions $\left(D_{\alpha}\right.$ and $\left.D_{\beta}\right)$ for each brick together with the external dose component $\left(D_{\gamma}\right)$.

\section{Age calculation}

Table 6 shows, respectively, the $E D$ values, the annual dose rates, the dating results for all the subsamples and the corresponding calendar dates.

\section{CONCLUSIONS}

The results obtained show that in the case where for each technique and method are conducted appropriate preliminary tests to equivalent dose measurements, a good convergence on the final data can be obtained.

In particular, the OSL procedures applied appear to reduce the dispersion on the final age compared to data obtained by TL on the fine grain phase. However the possibility of using a double SAR method for $E D$ measurement on fine grain fraction is closely related to the granulometric characteristics of the sample and also to its degree of feldspars content.

In addition, this procedure also needs larger amounts of sample because it is essential to carry out some preliminary studies before the evaluation of the equivalent dose such as the preheating and IR tests to found, respectively, the best preheating temperature and IR stimulation time.

However the samples collected from the Church of Saint Seurin permit to date the structure to the $4^{\text {th }}$ century. The age results obtained are not in contradiction with the stratigraphical and archaeological analysis of the site.

The present study shows that the imposed restraints on historical buildings dating regarding the limited number of

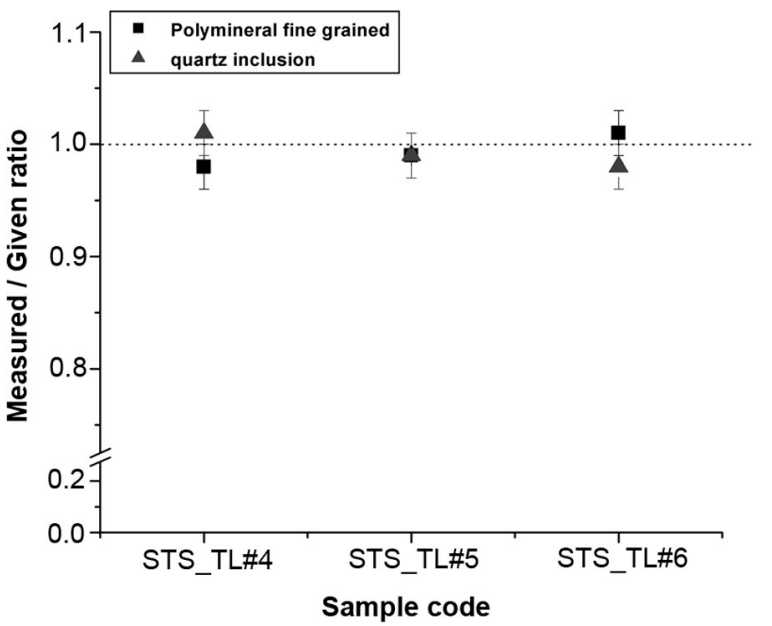

Fig. 6. Data obtained from dose recovery test (measured to given dose ratio) on the three analyzed samples (10 deviation). In the dSAR (FG*-OSL-dSAR) and SAR (QI-OSL-SAR) sequences, a preheat at $200^{\circ} \mathrm{C}$ for $10 \mathrm{~s}$ and at $180^{\circ} \mathrm{C}$ for $10 \mathrm{~s}$, were respectively performed both with a cut heat at $160^{\circ} \mathrm{C}$. 
Table 5. $k$ value determined for fine grain fraction by standard Added Dose (FG-TL-AD), porosity $W$ and saturation factor $F$, internal $D_{a}, D_{\beta}$ and external $D_{\gamma^{+}+o s m}$ contribution to annual dose.

\begin{tabular}{|c|c|c|c|c|c|c|c|}
\hline Sample & Subsample & k & w & $F$ & $\begin{array}{c}D_{\alpha}{ }^{(1)} \\
(m G y / a)\end{array}$ & $\begin{array}{c}D_{\beta}(1),(2) \\
(m G y / a) \\
\end{array}$ & $\begin{array}{c}D_{y+c o s m} \\
(\mathrm{mGy} / \mathrm{a}) \\
\end{array}$ \\
\hline \multirow{2}{*}{ STS_TL\#4 } & FG-TL-AD & $0.111 \pm 0.012$ & \multirow{2}{*}{$0.161 \pm 0.002$} & \multirow{2}{*}{$0.5 \pm 0.2$} & $18.58 \pm 1.09$ & $1.14 \pm 0.05$ & \multirow{2}{*}{$1.07 \pm 0.03$} \\
\hline & $\frac{F^{\text {FG-OSL-dSAR }}}{\text { QI-OSL-dSAR }}$ & $\frac{0.041 \pm 0.005}{-}$ & & & - & $1.05 \pm 0.05$ & \\
\hline \multirow{3}{*}{ STS_TL\#5 } & FG-TL-AD & $0.131 \pm 0.011$ & \multirow{3}{*}{$0.157 \pm 0.002$} & \multirow{3}{*}{$0.5 \pm 0.2$} & $19.32 \pm 1.12$ & $1.17 \pm 0.05$ & \multirow{3}{*}{$0.96 \pm 0.03$} \\
\hline & FG*-OSL-dSAR & $0.042 \pm 0.005$ & & & & & \\
\hline & QI-OSL-dSAR & - & & & - & $1.09 \pm 0.05$ & \\
\hline \multirow{2}{*}{ STS_TL\#6 } & FG-TL-AD & $0.133 \pm 0.012$ & \multirow{2}{*}{$0.218 \pm 0.002$} & \multirow{2}{*}{$0.5 \pm 0.2$} & $13.30 \pm 0.91$ & $2.18 \pm 0.12$ & \multirow{2}{*}{$1.05 \pm 0.04$} \\
\hline & OI-OSI - -dSAR & $0.052 \pm 0.005$ & & & - & $208+011$ & \\
\hline
\end{tabular}

${ }^{(1)} D_{\alpha}$ and $D_{\beta}$ are corrected for $W$ and $F$ factors.

(2) for $D_{\beta}$ by quartz inclusion were used following $f$ correction factors: $f_{U}=0.92, f_{T h}=0.91, f_{K}=0.96, f_{R b}=0.75$ (Mejdahl, 1979).

Table 6. Equivalent dose (ED), Dose rate, Age and Date values determined for each sample on fine grain fraction by standard Added Dose (FG-TL$A D$ ) and by dSAR (FG*-OSL-dSAR), and on quartz inclusion phase (QI-OSL-SAR) by SAR protocol.

\begin{tabular}{|c|c|c|c|c|c|}
\hline Sample & Subsample & $\begin{array}{l}\text { ED } \\
\text { (Gy) }\end{array}$ & $\begin{array}{c}\text { Dose rate } \\
\text { (mGy/a) }\end{array}$ & $\begin{array}{l}\text { Age } \\
\text { (a) }\end{array}$ & $\begin{array}{l}\text { Date } \\
\text { (A.D.) }\end{array}$ \\
\hline \multirow{3}{*}{ STS_TL\#4 } & FG-TL-AD & $6.88 \pm 0.51$ & $4.27 \pm 0.34$ & $1610 \pm 150$ & $400 \pm 150$ \\
\hline & FG*-OSL-dSAR & $4.75 \pm 0.22$ & $2.97 \pm 0.24$ & $1600 \pm 100$ & $410 \pm 100$ \\
\hline & $\overline{\text { QI-OSL-dSAR }}$ & $3.45 \pm 0.14$ & $2.13 \pm 0.12$ & $1620 \pm 110$ & $380 \pm 110$ \\
\hline \multirow{3}{*}{ STS_TL\#5 } & FG-TL-AD & $7.82 \pm 0.72$ & $4.66 \pm 0.36$ & $1680 \pm 180$ & $330 \pm 180$ \\
\hline & $\overline{\mathrm{FG}}{ }^{*}$-OSL-dSAR & $4.82 \pm 0.19$ & $2.94 \pm 0.23$ & $1640 \pm 100$ & $370 \pm 100$ \\
\hline & $\overline{\text { QI-OSL-dSAR }}$ & $3.30 \pm 0.11$ & $2.05 \pm 0.11$ & $1610 \pm 100$ & $390 \pm 100$ \\
\hline \multirow{3}{*}{ STS_TL\#6 } & FG-TL-AD & $8.21 \pm 0.47$ & $5.00 \pm 0.45$ & $1640 \pm 120$ & $370 \pm 120$ \\
\hline & FG*-OSL-dSAR & $6.32 \pm 0.33$ & $3.92 \pm 0.35$ & $1610 \pm 110$ & $400 \pm 110$ \\
\hline & $\overline{\text { QI-OSL-dSAR }}$ & $4.96 \pm 0.16$ & $3.13 \pm 0.20$ & $1580 \pm 110$ & $430 \pm 110$ \\
\hline
\end{tabular}

collected samples could be avoided crossing the results obtained on the same sample from different protocols.

\section{ACKNOWLEDGEMENTS}

This work was realised within the framework of the European research network (GdRE) "Architectural ceramics and dating methods". Special thanks to Armel Bouvier of the University of Bordeaux 3 and Pierre Guibert, director of CRPAA du CNRS de Bordeaux, for valuable discussions. We are pleased to acknowledge the technical assistance of Nunzio Giudice, Nunzio Guardone, Antonio Rapicavoli and Vito Sparti.

\section{REFERENCES}

Abrahamsen N, Jacobsen U, Mejdahl V and Mejdahl U, 1998. Magnetic investigations and datings of a brick kiln at Veldbaek near Esbjerg (Denmark). Physics and Chemistry of the Earth 23(9-10): 10151019, DOI 10.1016/S0079-1946(98)00135-9

Aitken MJ, 1985. Thermoluminescence Dating. Academic Press, London, $359 \mathrm{pp}$.

Aitken MJ, 1998. An introduction to Optical Dating. The Dating of Quaternary Sediments by the Use of Photon Stimulated Luminescence. Oxford Science Publications, Oxford, $267 \mathrm{pp}$.

Bailiff IK and Holland N, 2000. Dating bricks of the last two millennia from Newcastle upon Tyne: a preliminary study. Radiation Meas- urements 32(5-6): 615-619, DOI 10.1016/S1350-4487(99)002863.

Bailiff IK, 2007. Methodological developments in the luminescence dating of brick from English late-medieval and post-medieval buildings. Archaeometry 49(4): 827-851, DOI 10.1111/j.14754754.2007.00338.x.

Bøtter-Jensen MJ, Bulur E, Duller GAT and Murray AS, 2000. Advances in luminescence instrument systems. Radiation Measurements 32(5-6): 523-528, DOI 10.1016/S1350-4487(00)00039-1.

Bøtter-Jensen MJ, 1997. Luminescence techniques: instrumentation and methods. Radiation Measurements 27(5-6): 749-768, DOI 10.1016/S1350-4487(97)00206-0.

Cechák T, Gerndt J, Kubelík M, Musílek L and Pavlík M, 2000. Radiation methods in research of ancient monuments. Applied Radiation and Isotopes 53(4-5): 565-570, DOI 10.1016/S09698043(00)00221-9.

Duller GAT, 2007. Assessing the error on equivalent dose estimates derived from single aliquot regenerative dose measurements. Ancient TL 25: 15-24.

Feathers JK, Johnson J and Kembel SR, 2008. Luminescence Dating of Monumental Stone Architecture at Chavìn De Huántad, Perú. Journal of Archaelogical Method and Theory 15(3): 266-296, DOI 10.1007/s10816-008-9053-9.

Goedicke C, Slusallek K and Kubelik M, 1981. Thermoluminescence dating in architectural history: Venetian villas. Journal of the Society of Architectural Historians 40(3): 203-217, DOI $10.2307 / 989694$.

Göksu HY and Schwenk P, 2001. Investigation of the thermal stability of the $210^{\circ} \mathrm{C}$ TL peak of quartz and dating the components of terrazzo from the monastery church of Tergnsee. Radiation Measurements 33(5): 785-792, DOI 10.1016/S1350-4487(01)00107-X. 
Gueli AM, Stella G, Troja SO, Burrafato G, Margani G and Zuccarello AR, 2009. Absolute dating of the Cuba of Santa Domenica (Messina, Italy). Il Nuovo Cimento B 124(8): 885-891, DOI 10.1393/ncb/i2010-10818-2.

Gueli AM, Stella G, Troja SO, Burrafato G, Fontana D, Ristuccia GM and Zuccarello AR, 2010. Historical buildings: Luminescence dating of fine grains from bricks and mortar. Il Nuovo Cimento B 125(5-6): 719-729, DOI 10.1393/ncb/i2010-10892-4.

Guérin G, Mercier N and Adamiec G, 2011. Dose-rate conversion factors: update. Ancient TL 29: 5-8.

Guibert P, Vartanian E, Betchel F and Schvoerer M, 1996. Non linear approach of TL response to dose: polynomial approximation. Ancient TL 14(2): 7-14.

Guibert P, Bailiff IK, Blain S, Gueli AM, Martini M, Sibilia E, Stella G, Troja SO, 2009. Luminescence dating of architectural ceramics from an early medieval abbey: The St Philbert Intercomparison (Loire Atlantique, France). Radiation Measurements 44(5-6): 488-493, DOI 10.1016/j.radmeas.2009.06.006.

Hütt G, Göksu HY, Jaek I and Hiekkanen M, 2001. Luminescence dating of Somero sacristy, SW Finland using the $210^{\circ} \mathrm{C}$ TL peak in quartz. Quaternary Science Reviews 20(5-9): 773-777, DOI 10.1016/S0277-3791(00)00017-2.

Kiyak NG and Canel T, 2006. Equivalent dose in quartz from young samples using the SAR protocol and the effect of preheat temperature. Radiation Measurements 41(7-8): 917-922, DOI 10.1016/j.radmeas.2006.04.006.

Kim JC, Roberts HM, Duller GAT, Lee YI, Yi SB, 2009. Assessment of diagnostic tests for evaluating the reliability of SAR $D_{\mathrm{e}}$ values from polymineral and quartz fine grains. Radiation Measurements 44(2): 149-157, DOI 10.1016/j.radmeas.2009.01.003.

Martini M and Sibilia E, 2001. Radiation in archaeometry: archaeological dating. Radiation Physics and Chemistry 61(3-6): 241-246, DOI 10.1016/S0969-806X(01)00247-X.

Mauz B and Lang A, 2004. Removal of the feldspar-derived luminescence component from polymineral fine silt samples for optical dating applications: evaluation of chemical treatment protocols and quality control procedures. Ancient TL 22(1): 1-8.

Mejdahl V, 1979. Thermoluminescence dating: beta-dose attenuation in quartz grains. Archaeometry 21(1): 61-72, DOI 10.1111/j.14754754.1979.tb00241.x.

Murray AS and Wintle AG, 2000. Luminescence dating of quartz using an improved single-aliquot regenerative-dose protocol. Radiatiation Measurements 32(1): 57-73, DOI 10.1016/S13504487(99)00253-X.

Murray AS and Clemmensen LB, 2001. Luminescence dating of Holocene aeolian sand movement, Thy, Denmark. Quaternary Science Reviews 20(5-9): 751-754, DOI 10.1016/S0277-3791(00)00061-5.
Murray AS and Wintle AG, 2003. The single aliquot regenerative dose protocol: potential for improvements in reliability. Radiation Measurements 37(4-5): 377-381, DOI 10.1016/S13504487(03)00053-2.

Prasad S, 2000. HF treatment for the isolation of fine grain quartz for luminescence dating. Ancient TL 18(1): 15-17.

Prescott JR and Hutton JT, 1988. Cosmic ray and gamma ray dose dosimetry for TL and ESR. Nuclear Tracks and Radiation Measurements 14(1-2): 223-235, DOI 10.1016/1359-0189(88)90069-6.

Ramzaev V, Bøtter-Jensen L, Thomsen KJ, Andersson KG and Murray AS, 2008. An assessment of cumulative external doses from Chernobyl fallout for a forested area in Russia using the optically stimulated luminescence from quartz inclusions in bricks. Journal of Environmental Radioactivity 99(7): 1154-1164, DOI 10.1016/j.jenvrad.2008.01.014.

Rhodes EJ, 2000. Observations of thermal transfer OSL signals in glacigenic quartz. Radiation Measurements 32(5-6): 595-602, DOI 10.1016/S1350-4487(00)00125-6.

Roberts HM and Wintle AG, 2001. Equivalent dose determinations for polymineralic fine-grains using the SAR protocol: application to a Holocene sequence of the Chinese Loess Plateau. Quaternary Science Reviews 20(5-9): 859-863, DOI 10.1016/S02773791(00)00051-2.

Roberts HM, 2007. Assessing the effectiveness of the double-SAR protocol in isolating a luminescence signal dominated by quartz. Radiation Measurements 42(10): 1627-1636, DOI 10.1016/j.radmeas.2007.09.010.

Stella G, Fontana D, Gueli AM and Troja SO, 2013. Historical mortars dating from OSL signals of fine grain fraction enriched in quartz. Geochronometria 40(3): 153-164, DOI 10.2478/s13386-0130107-8.

Wallinga J, Murray AS, Duller GAT and Törnqvist TE, 2001. Testing optically stimulated luminescence dating of sand-sized quartz and feldspar from fluvial deposits. Earth and Planetary Science Letters 193(3-4): 617-630, DOI 10.1016/S0012-821X(01)00526-X.

Wang X, Lu Y and Zhao H, 2006. On the performances of the singlealiquot regenerative-dose (SAR) protocol for Chinese loess: fine quartz and polymineral grains. Radiation Measurements 41(1): 18, DOI 10.1016/j.radmeas.2005.02.010.

Zhang JF, Fan CF, Wang H and Zhou LP, 2007. Chronology of an oyster reef on the coast of Bohai Bay, China: Constraints from optical dating using different luminescence signals from fine quartz and polymineral fine grains of coastal sediments. Quaternary Geochronology 2(1-4): 71-76, DOI 10.1016/j.quageo.2006.05.027.

Zhang JF and Zhou LP, 2007. Optimization of the 'double SAR' procedure for polymineral fine grains, Radiation Measurements 42(9): 1475-1482, DOI 10.1016/j.radmeas.2007.06.007. 